\title{
Characteristics Associated With Functional Changes During Systemic Cancer Treatments: A Systematic Review Focused on Older Adults
}

\author{
Kah Poh Loh, MBBCh, BAO ${ }^{1, *}$; Vivian Lam, BA 2,*; Katey Webber, MPH³; Simran Padam, MD; Mina S. Sedrak, MD4; \\ Vivek Musinipally, MD'5 Madison Grogan, BA'; Carolyn J. Presley, MD'; Janice Grandi, BS²; Chandrika Sanapala, MS'; \\ Daniel A. Castillo, MLIS7; Grace DiGiovanni, BS ${ }^{1}$; Supriya G. Mohile, MD'1; Louise C. Walter, MD ${ }^{8,9}$; and Melisa L. Wong, MD 2,8,9
}

\begin{abstract}
Background: Maintaining functional status is important to older adults with cancer, but data are limited on how systemic treatments affect functional status. We systematically reviewed changes in functional status during systemic cancer treatments and identified characteristics associated with functional decline and improvement. Methods: We searched PubMed, Embase, Web of Science, and Cochrane Register of Controlled Trials for articles examining characteristics associated with functional changes in older adults during systemic cancer treatment published in English between database inception and January 11, 2019 (PROSPERO CRD42019123125). Findings were summarized with descriptive statistics. Study characteristics between older adult-specific and non-older adult-specific studies were compared using the Fisher exact test. Results: We screened 15,244 titles/abstracts and 519 full texts. The final analysis included 44 studies, which enrolled $>8,400$ patients; $39 \%$ of studies focused on older adults ( 1 study enrolled adults aged $\geq 60$ years, 10 enrolled adults aged $\geq 65$ years, and 6 enrolled adults aged $\geq 70$ years). Almost all studies (98\%) used patient-reported outcomes to measure functional status; only $20 \%$ used physical performance tests. Reporting of functional change was heterogeneous, with $48 \%$ reporting change scores. Older adult-specific studies were more likely to analyze functional change dichotomously (29\% vs $4 \%$; $P=.008$ ). Functional decline ranged widely, from $6 \%$ to $90 \%$. The most common patient characteristics associated with functional decline were older age ( $n=7$ studies), worse performance status $(n=4)$, progressive disease status $(n=4)$, pain $(n=4)$, anemia $(n=4)$, and worse nutritional status $(n=4)$. Twelve studies examined functional improvement and identified 11 unique associated characteristics. Conclusions: Functional decline is increasingly recognized as an important outcome in older adults with cancer, but definitions and analyses are heterogeneous, leading to a wide range of prevalence. To identify patients at highest risk of functional decline during systemic cancer treatments, trials need to routinely analyze functional outcomes and measure characteristics associated with decline (eg, nutrition).
\end{abstract}

J Natl Compr Canc Netw 2021;19(9):1055-1062 doi: $10.6004 /$ jnccn.2020.7684

See JNCCN.org for supplemental online content.

\section{Background}

Older adults with cancer are at increased risk for treatment toxicity and functional impairment, ${ }^{1-4}$ resulting in increased healthcare use and mortality. ${ }^{5-10}$ Maintaining functional status (FS) during cancer treatment is critically important to patients. More than $70 \%$ of older patients with cancer report that they would not choose a treatment that results in functional impairment, even if it improves survival. ${ }^{11}$ Despite the importance of functional outcomes to older adults, cancer clinical trials rarely capture the full impact of treatment on FS. Instead, trials focus on narrow definitions of treatment toxicity using provider-reported adverse effects, ${ }^{12}$ which do not capture FS or changes over time. As a result, limited data are available on how cancer treatments affect FS in older adults, hindering delivery of goalconcordant care.

Understanding how FS may change during systemic cancer treatment (eg, chemotherapy, immunotherapy, targeted therapy) and which patient characteristics are associated with these changes can inform shared decisionmaking to individualize cancer care. Identifying which patients are at highest risk of functional decline is

${ }^{1}$ Division of Hematology/Oncology, Department of Medicine, James P. Wilmot Cancer Institute, University of Rochester Medical Center, Rochester, New York; ${ }^{2}$ Division of Hematology/Oncology, Helen Diller Family Comprehensive Cancer Center, University of California, San Francisco, San Francisco, California; ${ }^{3}$ School of Public Health, University of California, Berkeley, Berkeley, California;

${ }^{4}$ Department of Medical Oncology and Therapeutics Research, City of Hope National Medical Center, Duarte, California; ${ }^{5}$ Department of Adult and Family Medicine, Kaiser Permanente, San Francisco, California; ${ }^{6}$ Division of Medical Oncology, Department of Internal Medicine, The Ohio State University Comprehensive Cancer Center, Columbus, Ohio; ${ }^{7}$ Edward G. Miner Library, University of Rochester School of Medicine and Dentistry, Rochester, New York; and ${ }^{8}$ Division of Geriatrics, University of California, San Francisco, and ${ }^{9}$ San Francisco Veterans Affairs Medical Center, San Francisco, California.

*These authors contributed equally to this manuscript. 
necessary to weigh the potential benefits and harms of treatment options, to better inform patient and caregiver anticipatory guidance, and to enable early introduction of tailored interventions, such as exercise and rehabilitation programs, to prevent functional impairment. ${ }^{13-15}$

Given the increasing recognition of the importance of FS in older adults with cancer ${ }^{16}$ and the explosion of new cancer treatments, an increasing number of studies have examined characteristics associated with FS change during treatment. Although a prior systematic review examined the prognostic and predictive value of FS at baseline, ${ }^{10}$ no review has systematically synthesized the literature on changes in FS during systemic cancer treatment. Therefore, we aimed to examine changes in FS during systemic cancer treatments with a focus on older adults and to identify patient characteristics associated with functional decline and improvement.

\section{Methods}

\section{Search Strategy and Selection Criteria}

This systematic review was conducted in accordance with the 2009 PRISMA guidelines. ${ }^{17}$ With a medical librarian (D.A. Castillo), we searched PubMed, Embase, Web of Science, and Cochrane Central Register of Controlled Trials for articles examining changes in FS during systemic cancer treatment among adults aged $\geq 65$ years published in English between database inception and January 11, 2019. Full search terms are shown in supplemental eTable 1 (available with this article at JNCCN.org) and included the following: "neoplasms," "cancer," "malignancy," or "tumor," AND "chemotherapy," "immunotherapy," or "antineoplastic," AND "functional status," "functional decline," "physical function," "mobility," "daily living activity," or "activities of daily living." This systematic review is registered with PROSPERO (CRD42019123125).

Studies were evaluated using these inclusion criteria: (1) the study included patients aged $\geq 65$ years with any cancer type; (2) participants received systemic cancer therapy; (3) FS was quantitatively measured using physical performance tests, patient-reported outcomes (PROs; eg, instrumental activities of daily living [IADLs]), physical well-being as part of a quality-of-life measure, physical activity (eg, step count), and/or clinicianreported performance status (PS); (4) FS was measured at $\geq 2$ time points (one before or during treatment such that change in FS during treatment could be ascertained); (5) FS was analyzed as an outcome; (6) the study reported an analysis of associations between patient characteristics and change in FS; and (7) the study was published in English. Studies of systemic therapy and other treatment modalities (eg, surgery) were included only if they reported results separately for patients who received systemic therapy. Notably, studies of concurrent chemoradiation were allowed because chemoradiation is the standard of care for some cancer types (eg, head and neck). In addition, studies of FS interventions (eg, exercise) were required to have control arms to allow evaluation of the effect of systemic cancer treatment on FS. Exclusion criteria included the following: (1) studies of hormone therapy, radiation, or surgery alone; (2) articles that did not report original data; and (3) full text was unavailable.

All identified articles were imported into Covidence (Veritas Health Innovation) and duplicates were removed. At each step described, discrepancies were resolved by consensus. Two investigators independently screened each title and abstract for eligibility. This evaluation was then repeated for full-text review. The final list of included full texts was used for data extraction.

\section{Data Extraction and Quality Appraisal}

A standardized template for data extraction was pilot tested. Two investigators independently extracted data for each study. Extracted data included first author, publication year, journal, geographic region, study design, intervention and control arms (if applicable), key inclusion criteria, sample size, age distribution, cancer treatment(s), measure(s) of FS, time points assessed, definition of change in FS, key findings, and characteristics associated with functional change.

Two investigators independently performed each appraisal of study quality using the National Heart, Lung, and Blood Institute (NHLBI) Quality Assessment Tool for Observational Cohort and Cross-Sectional Studies, which consists of 14 criteria. ${ }^{18}$ Example criteria included clearly defined research question, study population, inclusion criteria, and exposure and outcome measures. Participation rate and loss to follow-up were also considered. Meeting each criterion earned 1 point, and a summary score was calculated.

\section{Data Analysis}

Descriptive statistics were used to summarize study characteristics, including cancer type, measures of FS used (PROs, clinician-reported PS, physical performance test), assessment time points, and analytic approach. Fisher exact test was used to compare study characteristics between older adult-specific and non-older adult-specific studies. Characteristics associated with functional decline and improvement were summarized. No meta-analysis was planned a 
priori, given the heterogeneity in measures used to assess FS, cancer populations studied, and analytic methods.

\section{Results}

\section{Study Characteristics}

We screened 15,244 titles/abstracts and 519 full texts (supplemental eFigure 1). The final analysis included 44 studies, ${ }^{1,2,19-60}$ which were published from 1991 to 2019 (Figure 1) and enrolled $>8,400$ patients with cancer. Seventeen studies (39\%) focused on older adults (supplemental eTable 2), whereas 27 (61\%) included adults of all ages (supplemental eTable 3). Among the older adult-specific studies, which increased in number in recent years (Figure 1), one study enrolled only adults aged $\geq 60$ years, ${ }^{19} 10$ enrolled only adults aged $\geq 65$ years, ${ }^{1,2,20-27}$ and 6 enrolled only adults aged $\geq 70$ years. ${ }^{28-33}$ One-fourth of studies enrolled a heterogeneous population of patients with a solid or hematologic malignancy, and one-fourth enrolled patients with lung cancer. The next most common cancer types were breast cancer (16\%) and hematologic malignancies (16\%). Most studies (84\%) evaluated FS during chemotherapy, with only $5^{32,33,36,59,60}$ including targeted therapy and $2^{54,59}$ including immunotherapy.

\section{Quality Assessment}

Using the NHLBI Quality Assessment Tool for Observational Cohort and Cross-Sectional Studies, we found that the mean quality assessment score was 9.86 (range, 7-13; supplemental eTables 2 and 3). The most common reasons for lower study quality were lack of participation rate reporting, lack of sample size justification, loss to follow-up $\geq 20 \%$, and lack of adjustment for confounders. Outcome assessors were often not blinded to the patient's exposure status (eg, demographics). Only $59 \%$ of studies adjusted for key potential confounders in their analyses between patient characteristics and FS change.

\section{Measures of FS}

Almost all studies (98\%) used PROs to measure FS (Table 1). The most commonly used PRO was the EORTC Quality of Life Questionnaire-Core 30 (QLQC30) physical functioning scale ${ }^{61}$ (34\% of studies). Patient-reported activities of daily living (ADLs) (20\%) and IADLs (16\%) were also commonly used. Physical performance was tested in $20 \%$ of studies, with grip strength, chair stands, and walk tests being the most common. Traditional oncology measures of PS (eg, ECOG PS) were uncommon among included studies. There were no statistically significant differences in

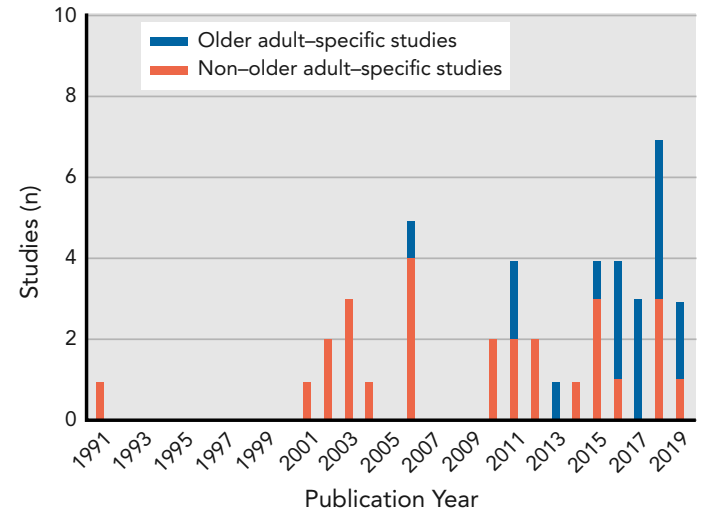

Figure 1. Included studies, by publication year.

FS measures used in older adult-specific versus non-older adult-specific studies.

\section{Assessment Time Points and Analytic Approach to FS}

Most studies assessed FS before starting systemic therapy and at 1 ( $20 \%$ of studies), 2 ( $14 \%$ ), or $\geq 3$ (50\%) follow-up time points, whereas $16 \%$ of studies performed the first assessment after therapy had started (Table 1). Analyses of FS change were heterogeneous, with many reporting change scores between 2 assessments (48\% of studies). Only $32 \%$ of studies used longitudinal methods to examine trajectories of FS over $\geq 2$ time points. The remaining studies analyzed FS change dichotomously by defining cutoff scores for decline and/or improvement ( $14 \%$ of studies), time to deterioration (5\%), or association with patient-reported change (2\%). Older adultspecific studies were more likely to analyze FS change dichotomously (29\% of older adult-specific studies vs $4 \%$ of non-older adult-specific studies; $P=.008$ ).

\section{Changes in FS and Associated Characteristics}

Among studies that reported the percentage of patients who developed functional decline, results ranged widely, from $6 \%{ }^{21}$ to $90 \%,{ }^{33}$ depending on the cancer type, treatment, measure of FS, and timing of assessments (supplemental eTables 2 and 3). Functional improvement occurred in between $9 \%^{55}$ and $57 \%^{21}$ of patients. The most common patient characteristics associated with functional decline during systemic cancer therapy (Table 2) were older age ( 7 studies $^{1,2,38,39,42,47,51}$ ), worse PS ( 4 studies $^{35,39,52,60}$ ), progressive disease status (4 studies ${ }^{2,31,35,60}$ ), pain (4 studies $^{24,35,39,45}$ ), anemia (4 studies ${ }^{1,20,24,47}$ ), and worse nutritional status (4 studies ${ }^{2,31-33}$ ). Definitions of these characteristics are listed in Table 2.

Only 12 studies $^{19,22,27,29,34,40-43,46,51,56}$ examined characteristics associated with functional improvement. Three articles $^{34,51,56}$ reporting results of a study of acute myeloid 


\begin{tabular}{|c|c|c|c|c|}
\hline Characteristic & $\begin{array}{l}\text { Overall } \\
\mathrm{n}(\%)\end{array}$ & $\begin{array}{l}\text { Older Adult-Specific Studies } \\
\text { n (\%) }\end{array}$ & $\begin{array}{l}\text { Non-Older Adult-Specific Studies } \\
\text { n (\%) }\end{array}$ & P Value ${ }^{a}$ \\
\hline Total, N & 44 & 17 & 27 & \\
\hline \multicolumn{5}{|l|}{ Measures of functional status } \\
\hline Patient-reported outcomes ${ }^{b}$ & $43(98)$ & $17(100)$ & $26(96)$ & 1.00 \\
\hline EORTC QLQ-C30 & $15(34)$ & $5(11)$ & $10(37)$ & \\
\hline ADLs & $9(20)$ & $7(16)$ & $2(7)$ & \\
\hline IADLs & $7(16)$ & $5(11)$ & $2(7)$ & \\
\hline Physical performance test ${ }^{\mathrm{b}}$ & $9(20)$ & $3(18)$ & $6(22)$ & 1.00 \\
\hline Grip strength & $8(18)$ & $3(18)$ & $5(19)$ & \\
\hline Walk tests & $6(14)$ & $3(19)$ & $3(11)$ & \\
\hline Chair stands & $5(11)$ & $1(12)$ & $4(15)$ & \\
\hline Clinician reported & $4(9)$ & $1(6)$ & $3(11)$ & 1.00 \\
\hline ECOG PS & $3(7)$ & $1(6)$ & $2(7)$ & \\
\hline KPS & $1(2)$ & $0(0)$ & $1(4)$ & \\
\hline Assessment time points & & & & .91 \\
\hline Pretreatment and 1 follow-up & $9(20)$ & $3(18)$ & $6(22)$ & \\
\hline Pretreatment and 2 follow-ups & $6(14)$ & $3(18)$ & $3(11)$ & \\
\hline Pretreatment and $\geq 3$ follow-ups & $22(50)$ & $8(47)$ & $14(52)$ & \\
\hline Other assessment schedule ${ }^{c}$ & $7(16)$ & $3(18)$ & $4(15)$ & \\
\hline Analytic approach & & & & .008 \\
\hline Change score between 2 assessments & $21(48)$ & $6(35)$ & $15(56)$ & \\
\hline Longitudinal analysis & $14(32)$ & $3(18)$ & $11(41)$ & \\
\hline Dichotomous functional decline & $6(14)$ & $5(29)$ & $1(4)$ & \\
\hline Time to deterioration & $2(5)$ & $2(12)$ & $0(0)$ & \\
\hline Other analysis ${ }^{d}$ & 1 (2) & $1(6)$ & $0(0)$ & \\
\hline
\end{tabular}

Abbreviations: ADLs, activities of daily living; EORTC QLQ-C30, EORTC Quality of Life Questionnaire-Core 30; IADLs, instrumental activities of daily living; KPS Karnofsky performance status; PS, performance status.

aFisher exact test comparing older adult-specific studies and non-older adult-specific studies.

bOnly the 3 most common measures of functional status within each subgroup are shown.

'Other assessment schedule: initial assessment occurred after initiation of systemic therapy.

dOther analysis: association with patient-reported change in physical condition.

leukemia found that younger age was associated with greater improvement in timed chair stands during intensive chemotherapy. Lower symptom burden was associated with greater improvement in FS in 3 studies..$^{22,40,41}$ Additional characteristics associated with greater functional improvement included female sex, ${ }^{56}$ married status, ${ }^{22}$ baseline functional dependence, ${ }^{27}$ better cognition, ${ }^{19}$ lack of depression, ${ }^{41}$ higher hemoglobin, ${ }^{42}$ cancer type, ${ }^{43,46}$ and $<4$ positive nodes (in a breast cancer study). ${ }^{22}$ In a randomized controlled trial of a cognitive behavioral therapy intervention, worse comorbidity was associated with greater improvement in FS in the intervention arm. ${ }^{41}$

\section{Discussion}

Over almost 3 decades of research from 1991 to 2019, we identified only 44 studies that included older adults and rigorously examined patient characteristics associated with FS change during systemic cancer treatment. Although the increasing number of studies in more recent years is promising, especially the increasing number of older adult-specific studies, the relative lack of studies examining FS as a longitudinal outcome highlights the importance of synthesizing the existing data and the ongoing need to add this patient-centered outcome to cancer clinical trials and observational cohort studies.

This systematic review identified a substantial amount of heterogeneity between studies in how FS is measured, when it is assessed during systemic cancer treatment, and how it is analyzed, limiting direct comparisons between studies. For example, functional decline was identified in $6 \%$ of women aged $\geq 65$ years with breast cancer in a trial of adjuvant therapy using patient-reported worsening physical condition. ${ }^{21}$ In contrast, with use of ADLs, functional 


\section{Table 2. Common Characteristics Associated With Functional Decline During Systemic Treatment ${ }^{\mathrm{a}}$}

\begin{tabular}{|c|c|c|c|c|c|}
\hline Characteristic & $\begin{array}{l}\text { Total Studies } \\
\text { Examining } \\
\text { Characteristic and } \\
\text { Functional Decline, } \mathbf{n}\end{array}$ & $\begin{array}{l}\text { Studies Reporting an } \\
\text { Association With } \\
\text { Functional Decline, n }\end{array}$ & $\begin{array}{l}\text { Studies Reporting No } \\
\text { Association, n }\end{array}$ & $\begin{array}{c}\text { Studies Including } \\
\text { Characteristic as a } \\
\text { Covariate Without } \\
\text { Reporting Association, n }\end{array}$ & Characteristic Variable Details ${ }^{b}$ \\
\hline Worse PS & 11 & $4^{35,39,52,60}$ & $6^{20,26,29-31,49}$ & $1^{19}$ & $\begin{array}{l}\text { - ECOG PS: 0-1 vs 2-460 } \\
\text { - Continuous KPS score }{ }^{39} \\
\text { - Change in ECOG/WHO PS }{ }^{35,52}\end{array}$ \\
\hline $\begin{array}{l}\text { Progressive } \\
\text { disease status }\end{array}$ & 8 & $4^{2,31,35,60}$ & $4^{19,42,49,60}$ & & $\begin{array}{l}\text { - Refractory/progressive disease } \\
\text { at treatment completion vs } \\
\text { complete remission } \\
\text { - Disease progression/relapse vs } \\
\text { new diagnosis } \\
\text { - Tumor response: partial/ } \\
\text { complete response vs } \\
\text { progressive/stable disease } \\
\text { - Disease progression: yes vs no }{ }^{30}\end{array}$ \\
\hline Pain & 7 & $4^{24,35,39,45}$ & $3^{26,31,47}$ & & $\begin{array}{l}\text { - Back pain: yes vs no no } \\
\text { - EORTC QLQ-C30 pain: quite a } \\
\text { bit/very much vs not at all/a little }{ }^{35} \\
\text { - Quality of Life-Cancer pain score }{ }^{39} \\
\text { - Pain-O-Meter worst pain intensity } \\
\text { score }^{45}\end{array}$ \\
\hline Anemia & 7 & $4^{1,20,24,47}$ & $3^{26,30,38}$ & & $\begin{array}{l}\text { - Categorical hemoglobin level: } \\
7.3-10.9,11.0-12.9,13.0-13.9, \\
14.0-15.6^{1} \\
\text { - Continuous hemoglobin level}\left.\right|^{24} \\
\text { - Hemoglobin change } \geq 1 \mathrm{~g} / \mathrm{dL}^{20} \\
\text { - Anemia CTCAE grade } 0-2 \mathrm{vs} \\
\text { 3-47 }\end{array}$ \\
\hline
\end{tabular}

Abbreviations: BMI, body mass index; EORTC QLQ-C30, EORTC Quality of Life Questionnaire-Core 30; KPS, Karnofsky performance status; PS, performance status. aStudies that examined functional decline $(\mathrm{N}=36)$.

${ }^{b}$ Characteristic variable details are shown for studies that reported an association with functional decline.

decline was identified in $90 \%$ of adults aged $\geq 70$ years with advanced non-small cell lung cancer receiving chemotherapy. ${ }^{33}$ Study populations also differed widely in cancer types and specific treatments evaluated. However, most studies included only chemotherapy, revealing a gap in understanding of the functional impact of immunotherapy and targeted therapy, which are key components of modern cancer care.

FS was most commonly assessed using PROs (98\% of studies), such as the EORTC QLQ-C30. ${ }^{61}$ The widespread use of PRO measures to assess FS among patients with cancer mirrors the broader surge of PROs used to assess symptoms and adverse effects during routine cancer care and in trials. ${ }^{62-65}$ Advantages of PRO FS measures in clinical care include the ability to assess FS outside of busy clinic visits (eg, previsit questionnaire), remotely without an in-person component (which is increasingly important during the COVID-19 pandemic), and with potentially fewer resources than available when conducting a physical performance test. PROs also allow FS to be more easily studied longitudinally in clinical trials or observational cohort studies in which FS is not the primary outcome. Compared with physical performance tests, PROs are more representative of the patient perspective about their FS. Furthermore, patient-reported functional 
decline in ADLs is a strong predictor of overall survival among older adults with cancer. ${ }^{31}$

Several challenges existed in the analysis of FS changes during systemic treatment. There were no uniform definitions of clinically meaningful functional decline or improvement. Despite half of the included studies measuring FS at $\geq 3$ follow-up assessments, $>60 \%$ only analyzed data from 2 time points, effectively ignoring informative patient-centered information. To illustrate, $48 \%$ of studies analyzed longitudinal FS as a change score between 2 assessments, and $14 \%$ used a threshold definition of a dichotomous functional decline outcome. Although these types of analytic approaches may assist in clinical interpretation (eg, percentage of patients who experience functional decline after one cycle of chemotherapy ${ }^{30}$ ), they do not capture FS trajectories that may include both declines and improvements. In contrast, Hurria et $\mathrm{al}^{22}$ combined more nuanced changes in FS over time and clinically applicable results by conducting 4 analyses using dichotomous outcomes to examine functional decline at the end of adjuvant breast cancer chemotherapy, functional decline at 12 months, improvement of FS among those with decline, and resistance to decline. This study exemplifies an alternative analytic approach that examines several time points and several definitions of FS change.

Older age, which was defined differently across studies, was the most common characteristic associated with functional decline. However, because many studies did not adjust for comorbidity, which is more common among older adults ${ }^{66}$ and associated with functional decline, ${ }^{5,24,29,49}$ there may have been residual confounding. We also found that worse PS, comorbidity, worse nutrition, presence of pain, and anemia were associated with functional decline, highlighting the importance of assessing and addressing these concerns. Evaluation of these characteristics and other domains important to older adults (eg, cognition) through geriatric assessment ${ }^{67}$ is necessary to comprehensively risk-stratify patients. Geriatric assessment results can guide recommendations to address modifiable risk factors via supportive care interventions (eg, physical therapy for worse PS) and comanagement with a multidisciplinary team (eg, palliative medicine for pain, dietitian for malnutrition). ${ }^{68}$

Some older adults with cancer do not experience functional decline during systemic treatment, some experience decline but later improve, and some never improve. "Resilience" refers to the process of adapting well in the face of a stressor ${ }^{69}$ or simply the ability to recover to baseline. ${ }^{22,70}$ Understanding characteristics associated with functional improvement can guide conversations regarding cancer treatment, because patients may be more willing to undergo treatment if they are likely to recover. Future studies should evaluate the underlying mechanisms by which these characteristics lead to functional improvement, which can guide development of interventions.

This systematic review had several limitations. First, our review focused on the effects of systemic cancer therapy on FS changes and did not examine surgery or radiation. Second, we included only studies that reported results separately for patients who received systemic therapy. Therefore, studies were excluded that examined FS changes in a heterogeneous sample of patients with cancer receiving a variety of treatments. In addition, we focused on studies examining patient characteristics associated with functional decline and improvement rather than performing a comprehensive review of the prevalence of functional change. Finally, because of heterogeneity of patient populations, FS measures, time points, and analytic approaches, a meta-analysis was not possible.

Future studies of cancer treatments in older adults, particularly beyond chemotherapy, must include serial FS measures and analyze these data to determine which older patients are at highest risk of functional decline and which may be more resilient. Measurement of characteristics associated with functional decline, such as nutritional status, which is absent from many trials, is equally important. This is especially critical given the rapidly evolving treatment landscape and the need to understand how newer therapies impact older adults. Many cancer trials already contain a collection of valuable, unanalyzed FS information as part of broader quality-of-life questionnaires. These data have the potential to greatly expand the knowledge base on FS changes during cancer treatment and to inform shared decision-making with information on this important patient-centered outcome.

Furthermore, the development of risk prediction tools, such as risk scores or nomograms, would make information about characteristics associated with FS change more clinically accessible for patient care and shared decision-making. Examples of successful translations of research data into clinical practice include the Cancer and Aging Research Group chemotherapy toxicity calculator ${ }^{71,72}$ and the ePrognosis.org collection of prognostic indices (https://eprognosis.ucsf. edu/). ${ }^{73}$ Studies of FS changes among older adults with the same cancer type are also needed to make results less heterogeneous and more clinically applicable.

\section{Conclusions}

There is increasing recognition that change in FS is an important outcome among older patients with cancer 
receiving systemic treatment. However, definitions and analyses of functional decline and improvement are heterogeneous, leading to a wide range of prevalence. To better understand functional decline and improve outcomes in this vulnerable population, measures of FS outcomes need to be incorporated with traditional oncology outcomes.

Submitted August 7, 2020; final revision received October 30, 2020 accepted for publication October 12, 2020

Published online April 15, 2021.

Author contributions: Literature search: Loh, Lam, Castillo, Wong Study design: Loh, Lam, Webber, Castillo, Walter, Wong. Data analysis and interpretation: Loh, Lam, Webber, Padam, Sedrak, Musinipally, Grogan, Presley, Grandi, Sanapala, DiGiovanni, Mohile, Walter, Wong.

Manuscript preparation: Loh, Lam, Wong. Critical revision: All authors.

Disclosures: Dr. Loh has disclosed serving as a consultant for Pfizer and
Seattle Genetics. Dr. Sedrak has disclosed receiving grant/research support from Seattle Genetics, Novartis, Eli Lilly, and Pfizer. Dr. Wong has disclosed having an immediate family member who is employed of Genentech with stock ownership. The remaining authors have disclosed that they have not received any financial consideration from any person or organization to support the preparation, analysis, results, or discussion of this article.

Funding: Research reported in this publication was supported by the $\mathrm{NCl}$ of the NIH under award numbers K99CA237744 (K.P. Loh) and K12CA001727 (M.S. Sedrak); the National Institute on Aging of the NIH under grants R03AG064377 (M.S. Sedrak), K24AG056589 and R33AG059206 (S.G. Mohile), P30AG044281 (L.C. Walter and M.L. Wong) and K76AG064431 and R03AG056439 (M.L. Wong); a Wilmot Research Fellowship Award (K.P. Loh); and funding from the University of California, San Francisco Helen Diller Family Comprehensive Cancer Center (M.L. Wong)

Disclaimer: The content is solely the responsibility of the authors and does not necessarily represent the official views of the NIH.

Correspondence: Melisa L. Wong, MD, Divisions of Hematology/Oncology and Geriatrics, Helen Diller Family Comprehensive Cancer Center, University of California, San Francisco, 550 16th Street, Box 1770, San Francisco, CA 94143. Email: melisa.wong@ucsf.edu

\section{References}

1. Goodwin JA, Coleman EA, Shaw J. Short Functional Dependence Scale: development and pilot test in older adults with cancer. Cancer Nurs 2006; 29:73-81.

2. Rier HN, Jager A, Meinardi MC, et al. Severe sarcopenia might be associated with a decline of physical independence in older patients undergoing chemotherapeutic treatment. Support Care Cancer 2018;26: 1781-1789.

3. Crombag MBS, de Vries Schultink AHM, van Doremalen JGC, et al. Ageassociated hematological toxicity in patients with metastatic castrationresistant prostate cancer treated with docetaxel in clinical practice. Drugs Aging 2019;36:379-385.

4. Lund CM, Vistisen KK, Dehlendorff C, et al. Age-dependent differences in first-line chemotherapy in patients with metastatic colorectal cancer: the DISCO study. Acta Oncol 2018;57:1445-1454.

5. DuMontier C, Liu MA, Murillo A, et al. Function, survival, and care utilization among older adults with hematologic malignancies. J Am Geriatr Soc 2019;67:889-897

6. Liu MA, DuMontier C, Murillo A, et al. Gait speed, grip strength, and clinical outcomes in older patients with hematologic malignancies. Blood 2019;134:374-382.

7. Tang $\mathrm{V}$, Zhao S, Boscardin J, et al. Functional status and survival after breast cancer surgery in nursing home residents. JAMA Surg 2018;153: 1090-1096.

8. Maione P, Perrone F, Gallo C, et al. Pretreatment quality of life and functional status assessment significantly predict survival of elderly patients with advanced non-small-cell lung cancer receiving chemotherapy: a prognostic analysis of the multicenter Italian Lung Cancer in the Elderly Study. J Clin Oncol 2005;23:6865-6872.

9. Bruijnen CP, van Harten-Krouwel DG, Koldenhof JJ, et al. Predictive value of each geriatric assessment domain for older patients with cancer: a systematic review. J Geriatr Oncol 2019;10:859-873.

10. Couderc AL, Boulahssass R, Nouguerède $E$, et al. Functional status in a geriatric oncology setting: a review. J Geriatr Oncol 2019;10:884-894.

11. Fried TR, Bradley EH, Towle VR, et al. Understanding the treatment preferences of seriously ill patients. N Engl J Med 2002;346:1061-1066.

12. Common Terminology Criteria for Adverse Events (CTCAE), Version 5.0. Bethesda, MD: NCl; 2017.

13. Fairman $C M$, Focht $B C$, Lucas $A R$, et al. Effects of exercise interventions during different treatments in breast cancer. J Community Support Oncol 2016:14:200-209.

14. Buffart LM, Sweegers MG, May AM, et al. Targeting exercise interventions to patients with cancer in need: an individual patient data meta-analysis. J Natl Cancer Inst 2018;110:1190-1200.

15. Stout NL, Baima J, Swisher AK, et al. A systematic review of exercise systematic reviews in the cancer literature (2005-2017). PM R 2017;9: S347-384

16. Mohile SG, Dale W, Somerfield MR et al. Practical assessment and management of vulnerabilities in older patients receiving chemotherapy: ASCO guideline for geriatric oncology. J Clin Oncol 2018;36: $2326-2347$
17. Moher D, Liberati A, Tetzlaff J, et al. Preferred Reporting Items for Systematic Reviews and Meta-Analyses: the PRISMA statement. BMJ 2009, 339:b2535.

18. NIH, National, Heart, Lung, and Blood Institute. Study quality assessment tools: Quality Assessment Tool for Observational Cohort and CrossSectional Studies. Accessed June 1, 2020. Available at: https://www.nhlbi. nih.gov/health-topics/study-quality-assessment-tools

19. Klepin HD, Tooze JA, Pardee TS, et al. Effect of intensive chemotherapy on physical, cognitive, and emotional health of older adults with acute myeloid leukemia. J Am Geriatr Soc 2016;64:1988-1995.

20. Doni L, Perin A, Manzione L, et al. The impact of anemia on quality of life and hospitalisation in elderly cancer patients undergoing chemotherapy. Crit Rev Oncol Hematol 2011;77:70-77.

21. Gajra A, McCall L, Muss HB, et al. The preference to receive chemotherapy and cancer-related outcomes in older adults with breast cancer CALGB 49907 (Alliance). J Geriatr Oncol 2018;9:221-227.

22. Hurria A, Soto-Perez-de-Celis E, Allred JB, et al. Functional decline and resilience in older women receiving adjuvant chemotherapy for breast cancer. J Am Geriatr Soc 2019;67:920-927.

23. Manokumar $\mathrm{T}$, Aziz $\mathrm{S}$, Breunis $\mathrm{H}$, et al. A prospective study examining elder-relevant outcomes in older adults with prostate cancer undergoing treatment with chemotherapy or abiraterone. J Geriatr Oncol 2016;7:81-89.

24. Miaskowski C, Wong ML, Cooper BA, et al. Distinct physical function profiles in older adults receiving cancer chemotherapy. J Pain Symptom Manage 2017;54:263-272.

25. Verelst SG, Termorshuizen F, Uyl-de Groot CA, et al. Effect of thalidomide with melphalan and prednisone on health-related quality of life (HRQoL) in elderly patients with newly diagnosed multiple myeloma: prospective analysis in a randomized trial. Ann Hematol 2011;90: 1427-1439.

26. Wong ML, Paul SM, Mastick J, et al. Characteristics associated with physical function trajectories in older adults with cancer during chemotherapy. J Pain Symptom Manage 2018;56:678-688.e1.

27. Xue D, Han S, Jiang S, et al. Comprehensive geriatric assessment and traditional Chinese medicine intervention benefit symptom control in elderly patients with advanced non-small cell lung cancer. Med Oncol 2015;32:114.

28. Chakiba C, Bellera C, Etchepare F, et al. The prognostic value of G8 for functional decline. J Geriatr Oncol 2019;10:921-925

29. Fiteni F, Anota A, Bonnetain F, et al. Health-related quality of life in elderly patients with advanced non-small cell lung cancer comparing carboplatin and weekly paclitaxel doublet chemotherapy with monotherapy. Eur Respir J 2016;48:861-872

30. Hoppe $\mathrm{S}$, Rainfray $\mathrm{M}$, Fonck $\mathrm{M}$, et al. Functional decline in older patients with cancer receiving first-line chemotherapy. J Clin Oncol 2013;31: 3877-3882

31. Kenis C, Decoster L, Bastin J, et al. Functional decline in older patients with cancer receiving chemotherapy: a multicenter prospective study. J Geriatr Oncol 2017:8:196-205. 
32. Morikawa A, Naito T, Sugiyama M, et al. Impact of cancer cachexia on hospitalization-associated physical inactivity in elderly patients with advanced non-small-cell lung cancer. Asia Pac J Oncol Nurs 2018;5: 377-382.

33. Naito T, Okayama T, Aoyama T, et al. Unfavorable impact of cancer cachexia on activity of daily living and need for inpatient care in elderly patients with advanced non-small-cell lung cancer in Japan: a prospective longitudinal observational study. BMC Cancer 2017;17:800

34. Alibhai SM, Breunis H, Timilshina N, et al. Quality of life and physical function in adults treated with intensive chemotherapy for acute myeloid leukemia improve over time independent of age. J Geriatr Oncol 2015;6: 262-271.

35. Bergman B, Sullivan M, Sörenson S. Quality of life during chemotherapy for small cell lung cancer. I. An evaluation with generic health measures. Acta Oncol 1991;30:947-957

36. Bezjak A, Tu D, Seymour $L$, et al. Symptom improvement in lung cancer patients treated with erlotinib: quality of life analysis of the National Cancer Institute of Canada Clinical Trials Group study BR.21. J Clin Oncol 2006;24:3831-3837.

37. Chen H, Cantor A, Meyer J, et al. Can older cancer patients tolerate chemotherapy? A prospective pilot study. Cancer 2003;97:1107-1114.

38. de Jong N, Candel MJ, Schouten HC, et al. Course of the fatigue dimension "activity level" and the interference of fatigue with daily living activities for patients with breast cancer receiving adjuvant chemotherapy. Cancer Nurs 2006;29:E1-13.

39. Dodd MJ, Miaskowski C, Paul SM. Symptom clusters and their effect on the functional status of patients with cancer. Oncol Nurs Forum 2001;28: 465-470.

40. Dodd MJ, Cho MH, Cooper BA, et al. The effect of symptom clusters on functional status and quality of life in women with breast cancer. Eur J Oncol Nurs 2010;14:101-110.

41. Doorenbos A, Given B, Given C, et al. Physical functioning: effect of behavioral intervention for symptoms among individuals with cancer. Nurs Res 2006;55:161-171.

42. Fallowfield L, Gagnon D, Zagari M, et al. Multivariate regression analyses of data from a randomised, double-blind, placebo-controlled study confirm quality of life benefit of epoetin alfa in patients receiving nonplatinum chemotherapy. Br J Cancer 2002;87:1341-1353.

43. Frödin U, Börjeson S, Lyth J, et al. A prospective evaluation of patients' health-related quality of life during auto-SCT: a 3-year follow-up. Bone Marrow Transplant 2011;46:1345-1352.

44. Frödin U, Lotfi K, Fomichov $V$, et al. Frequent and long-term follow-up of health-related quality of life following allogeneic haematopoietic stem cell transplantation. Eur J Cancer Care (Engl) 2015;24:898-910.

45. Gaton-Johansson F, Watkins CC, Kanu IK, et al. The effects of symptoms on quality of life during chemotherapy in African-American women with breast cancer. J Natl Black Nurses Assoc 2015;26:7-16.

46. Given B, Given CW, McCorkle R, et al. Pain and fatigue management: results of a nursing randomized clinical trial. Oncol Nurs Forum 2002;29: 949-956.

47. Greimel ER, Bjelic-Radisic V, Pfisterer J, et al. Randomized study of the Arbeitsgemeinschaft Gynaekologische Onkologie Ovarian Cancer Study Group comparing quality of life in patients with ovarian cancer treated with cisplatin/paclitaxel versus carboplatin/paclitaxel. J Clin Oncol 2006 24:579-586.

48. Kim BJ, Park HR, Roh HJ, et al. Chemotherapy-related polyneuropathy may deteriorate quality of life in patients with B-cell lymphoma. Qual Life Res 2010;19:1097-1103.

49. Kinsey E, Ajazi E, Wang X, et al. Predictors of physical and functional loss in advanced-stage lung cancer patients receiving platinum chemotherapy. J Thorac Oncol 2018;13:1294-1301.

50. Land SR, Kopec JA, Yothers G, et al. Health-related quality of life in axillary node-negative, estrogen receptor-negative breast cancer patients undergoing $A C$ versus CMF chemotherapy: findings from the National Surgical Adjuvant Breast and Bowel Project B-23. Breast Cancer Res Treat 2004;86:153-164.

51. Mohamedali $\mathrm{H}$, Breunis $\mathrm{H}$, Timilshina $\mathrm{N}$, et al. Older age is associated with similar quality of life and physical function compared to younger age during intensive chemotherapy for acute myeloid leukemia. Leuk Res 2012:36:1241-1248.
52. Morita S, Kobayashi K, Eguchi K, et al. Influence of clinical parameters on quality of life during chemotherapy in patients with advanced non-smal cell lung cancer: application of a general linear model. Jpn J Clin Oncol 2003:33:470-476.

53. Oechsle K, Jensen W, Schmidt T, et al. Physical activity, quality of life, and the interest in physical exercise programs in patients undergoing palliative chemotherapy. Support Care Cancer 2011;19:613-619.

54. Revicki DA, van den Eertwegh AJ, Lorigan $P$, et al. Health related quality of life outcomes for unresectable stage III or IV melanoma patients receiving ipilimumab treatment. Health Qual Life Outcomes 2012;10:66.

55. Shallwani SM, Simmonds MJ, Kasymjanova G, et al. Quality of life, symptom status and physical performance in patients with advanced nonsmall cell lung cancer undergoing chemotherapy: an exploratory analysis of secondary data. Lung Cancer 2016;99:69-75.

56. Timilshina N, Breunis $\mathrm{H}$, Tomlinson GA, et al. Long-term recovery of quality of life and physical function over three years in adult survivors of acute myeloid leukemia after intensive chemotherapy. Leukemia 2019;33:15-25.

57. Verdonck-de Leeuw IM, Buffart LM, Heymans MW, et al. The course of health-related quality of life in head and neck cancer patients treated with chemoradiation: a prospective cohort study. Radiother Oncol 2014;110: 422-428.

58. Watters JM, Yau JC, O'Rourke K, et al. Functional status is well maintained in older women during adjuvant chemotherapy for breast cancer. Ann Oncol 2003;14:1744-1750.

59. Williamson TJ, Choi AK, Kim JC, et al. A longitudinal investigation of internalized stigma, constrained disclosure, and quality of life across 12 weeks in lung cancer patients on active oncologic treatment. J Thorac Oncol 2018;13:1284-1293.

60. Yang SC, Lin CC, Lai WW, et al. Dynamic changes in quality of life after three first-line therapies for EGFR mutation-positive advanced non-smallcell lung cancer. Ther Adv Med Oncol 2018;10:1758834018755072.

61. Aaronson NK, Ahmedzai S, Bergman B, et al. The European Organization for Research and Treatment of Cancer QLQ-C30: a quality-of-life instrument for use in international clinical trials in oncology. J Natl Cancer Inst 1993;85:365-376.

62. Basch E, Rogak LJ, Dueck AC. Methods for implementing and reporting patient-reported outcome (PRO) measures of symptomatic adverse events in cancer clinical trials. Clin Ther 2016;38:821-830

63. Basch E, Deal AM, Kris MG, et al. Symptom monitoring with patientreported outcomes during routine cancer treatment: a randomized controlled trial. J Clin Oncol 2016;34:557-565.

64. Basch E, Deal AM, Dueck AC, et al. Overall survival results of a trial assessing patient-reported outcomes for symptom monitoring during routine cancer treatment. JAMA 2017;318:197-198.

65. Basch E, Reeve BB, Mitchell SA, et al. Development of the National Cancer Institute's patient-reported outcomes version of the Common Terminology Criteria for Adverse Events (PRO-CTCAE). J Natl Cancer Inst 2014;106:dju244.

66. Fowler $\mathrm{H}$, Belot $\mathrm{A}$, Ellis $\mathrm{L}$, et al. Comorbidity prevalence among cancer patients: a population-based cohort study of four cancers. BMC Cancer 2020;20:2.

67. Hurria A, Cirrincione CT, Muss HB, et al. Implementing a geriatric assessment in cooperative group clinical cancer trials: CALGB 360401. J Clin Oncol 2011;29:1290-1296.

68. Mohile SG, Velarde C, Hurria A, et al. Geriatric assessment-guided care processes for older adults: a Delphi consensus of geriatric oncology experts. J Natl Compr Canc Netw 2015;13:1120-1130.

69. Piccirillo JF, Tierney RM, Costas I, et al. Prognostic importance of comorbidity in a hospital-based cancer registry. JAMA 2004;291: 2441-2447.

70. Duan-Porter W, Cohen HJ, Demark-Wahnefried W, et al. Physical resilience of older cancer survivors: an emerging concept. J Geriatr Oncol $2016 ; 7: 471-478$

71. Hurria A, Togawa K, Mohile SG, et al. Predicting chemotherapy toxicity in older adults with cancer: a prospective multicenter study. J Clin Oncol 2011;29:3457-3465

72. Cancer and Aging Research Group. Chemotherapy toxicity prediction tool. Accessed June 30, 2020. Available at: http://www.mycarg.org/ Chemotherapy_Toxicity_Calculator

73. Yourman LC, Lee SJ, Schonberg MA, et al. Prognostic indices for older adults: a systematic review. JAMA 2012;307:182-192. 


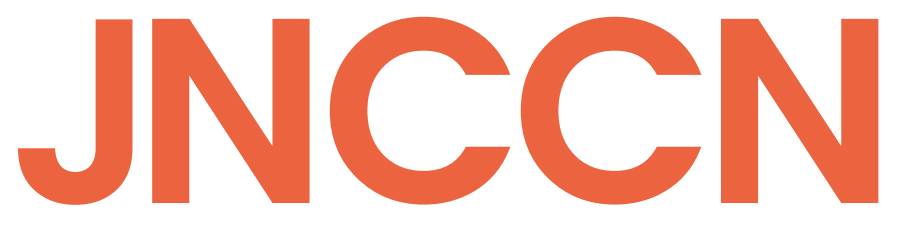

National

Comprehensive

Cancer

Network $^{\oplus}$

JOURNAL OF THE NATIONAL COMPREHENSIVE CANCER NETWORK

Supplemental online content for:

\section{Characteristics Associated With Functional Changes During Systemic Cancer Treatments: A Systematic Review Focused on Older Adults}

Kah Poh Loh, MBBCh, BAO; Vivian Lam, BA; Katey Webber, MPH; Simran Padam, MD; Mina S. Sedrak, MD; Vivek Musinipally, MD; Madison Grogan, BA; Carolyn J. Presley, MD; Janice Grandi, BS; Chandrika Sanapala, MS; Daniel A. Castillo, MLIS; Grace DiGiovanni, BS; Supriya G. Mohile, MD; Louise C. Walter, MD; and Melisa L. Wong, MD

J Natl Compr Canc Netw 2021;19(9):1055-1062

eFigure 1: Study Selection Flowchart

eTable 1: Search Strategies

eTable 2: Older Adult-Specific Studies Meeting Inclusion Criteria and Primary Functional Status Results eTable 3: Non-Older Adult-Specific Studies Meeting Inclusion Criteria and Primary Functional Status Results 


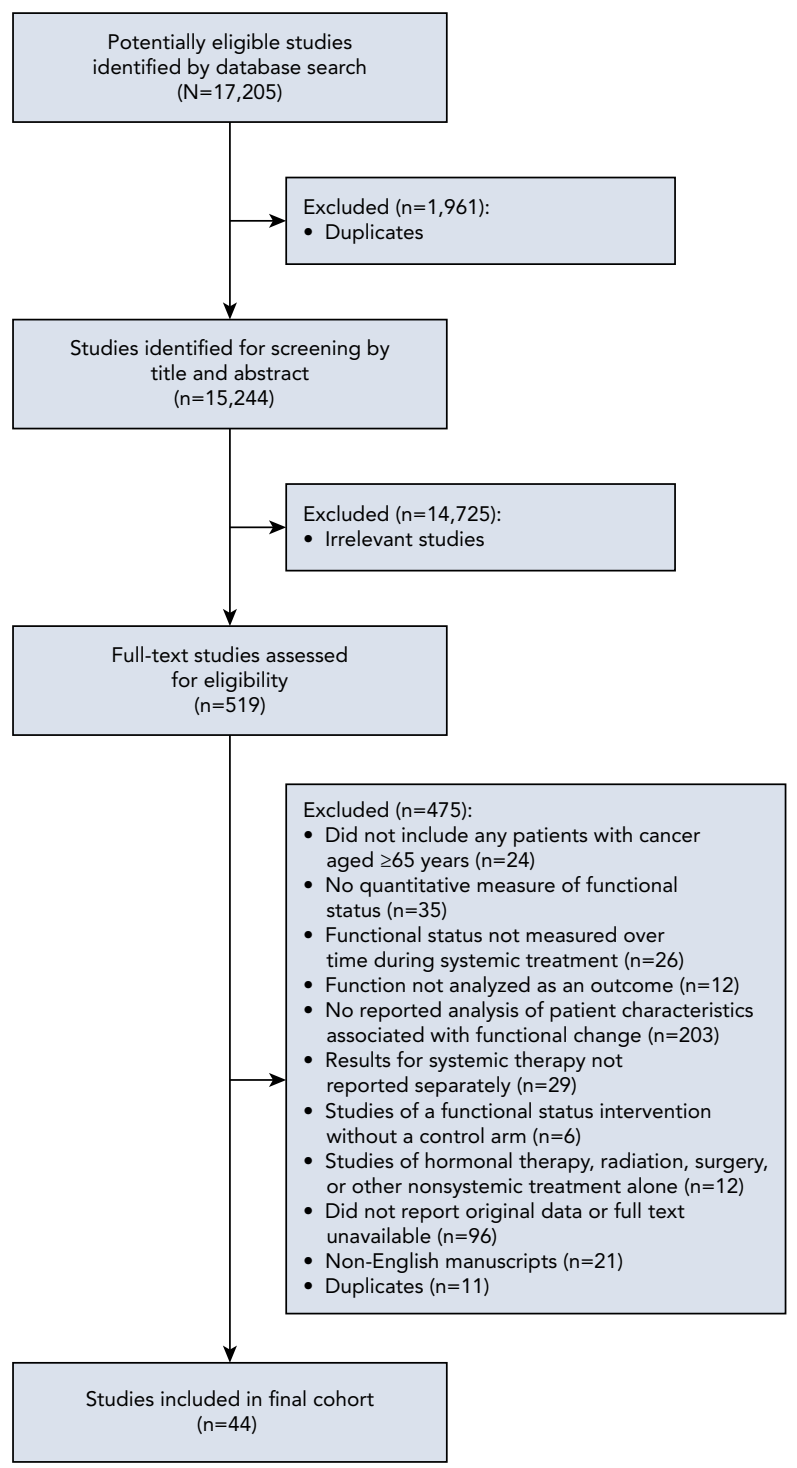

eFigure 1. Study selection flowchart. 
eTable 1. Search Strategies

\section{Database}

PubMed

\section{Search Strategy}

("Neoplasms"[MeSH] OR Neoplas*[tiab] OR Cancer*[tiab] OR Malignan*[tiab] OR Carcin*[tiab] OR Oncolog* [tiab] OR Tumor*[tiab] OR Tumor*[tiab])

AND

("Consolidation Chemotherapy"[MeSH] OR "Antineoplastic Combined Chemotherapy Protocols"[MeSH] OR "Induction Chemotherapy"[MeSH] OR "Maintenance Chemotherapy"[MeSH] OR

"Chemoradiotherapy"[MeSH] OR "Chemotherapy, Adjuvant"[MeSH] OR "Antineoplastic Protocols"[MeSH]

OR "Radioimmunotherapy"[MeSH] OR "Antineoplastic Agents"[MeSH] OR Chemotherap* OR

Antineoplastic* OR Anticancer OR Antitumor OR Antitumour OR Chemoradiotherap* OR

Radiochemotherap* OR Radioimmunotherap* OR "Immunotherapy"[MeSH] OR Immunotherap* OR

"Molecular Targeted Therapy"[MeSH] OR "Targeted Therapies"[tiab] OR "Targeted Therapy"[tiab])

AND

("Physical Functional Performance"[MeSH] OR "Functional Decline"[tiab] OR "Functional Status"[tiab] OR "Physical Function"[tiab] OR "Mobility"[tiab] OR "Activities of Daily Living"[MeSH] OR "Activity of Daily Living"[tiab] OR "Activities of Daily Living"[tiab] OR ADL[tiab] OR "Daily Living Activity"[tiab] OR "Daily Living Activities"[tiab])

Embase ('neoplasm'/exp OR neoplas* OR cancer OR malignan* OR carcin* OR oncolog* OR tumor* OR tumor ${ }^{\star}$ ) AND

('chemotherapy'/exp OR 'consolidation chemotherapy'/exp OR 'induction chemotherapy'/exp OR 'maintenance chemotherapy'/exp OR 'chemoradiotherapy'/exp OR 'adjuvant chemotherapy'/exp OR 'radioimmunotherapy'/exp OR 'antineoplastic agent'/exp OR chemotherap* OR antineoplastic* OR anticancer OR antitumor OR antitumour OR chemoradiotherap* OR radiochemotherap* OR radioimmunotherap* OR 'immunotherapy'/exp OR immunotherap* OR 'molecularly targeted therapy'/exp OR 'targeted therap ${ }^{\star \prime}$ )

AND

('functional decline'/exp OR 'functional decline' OR 'functional status'/exp OR 'functional status' OR 'functional performance'/exp OR 'functional performance' OR 'physical function'/exp OR 'physical function' OR 'patient mobility'/exp OR mobility OR 'daily life activity'/exp OR 'activit* of daily living' OR adl OR 'daily living activit*')

Web of Science: all databases

(Neoplas* OR Cancer* OR Malignan* OR Carcin* OR Oncolog* OR Tumor* OR Tumor*) AND

(Chemotherap* OR Antineoplastic* OR Anticancer OR Antitumor OR Antitumour OR Chemoradiotherap* OR Radiochemotherap* OR Radioimmunotherap* OR Immunotherap* OR "Targeted Therapies" OR "Targeted Therapy")

AND

("Functional Decline" OR "Functional Status" OR "Physical Function" OR Mobility OR "Activity of Daily Living" OR "Activities of Daily Living" OR ADL OR "Daily Living Activity" OR "Daily Living Activities")

Cochrane Register of Controlled Trials

(Neoplas* OR Cancer* OR Malignan* OR Carcin* OR Oncolog* OR Tumor* OR Tumor*)

AND

(Chemotherap* OR Antineoplastic* OR Anticancer OR Antitumor OR Antitumour OR Chemoradiotherap* OR Radiochemotherap* OR Radioimmunotherap* OR Immunotherap* OR "Targeted Therapies" OR "Targeted Therapy")

AND

("Functional Decline" OR "Functional Status" OR "Physical Function" OR Mobility OR "Activity of Daily Living" OR "Activities of Daily Living" OR ADL OR "Daily Living Activity" OR "Daily Living Activities") 


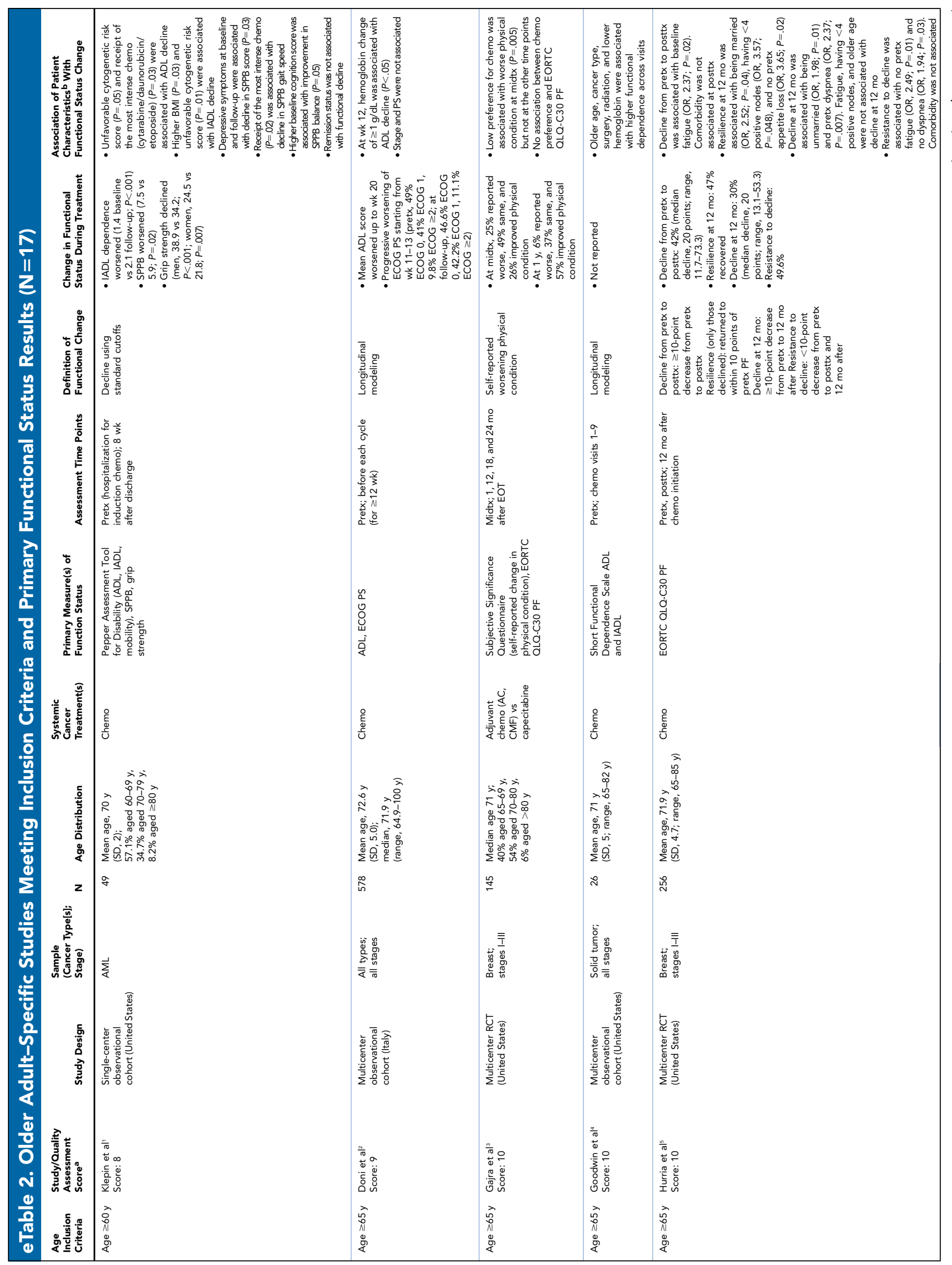




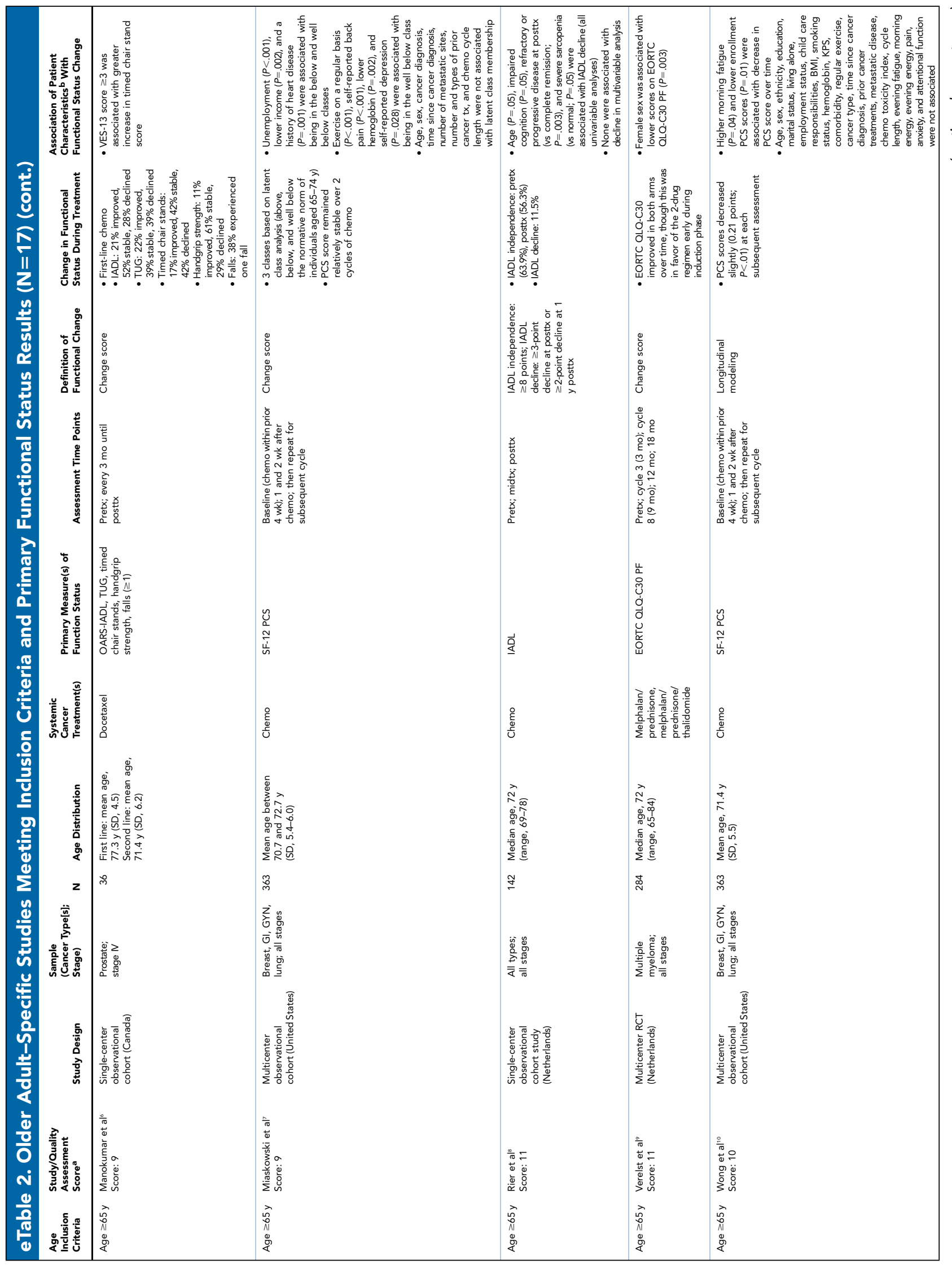




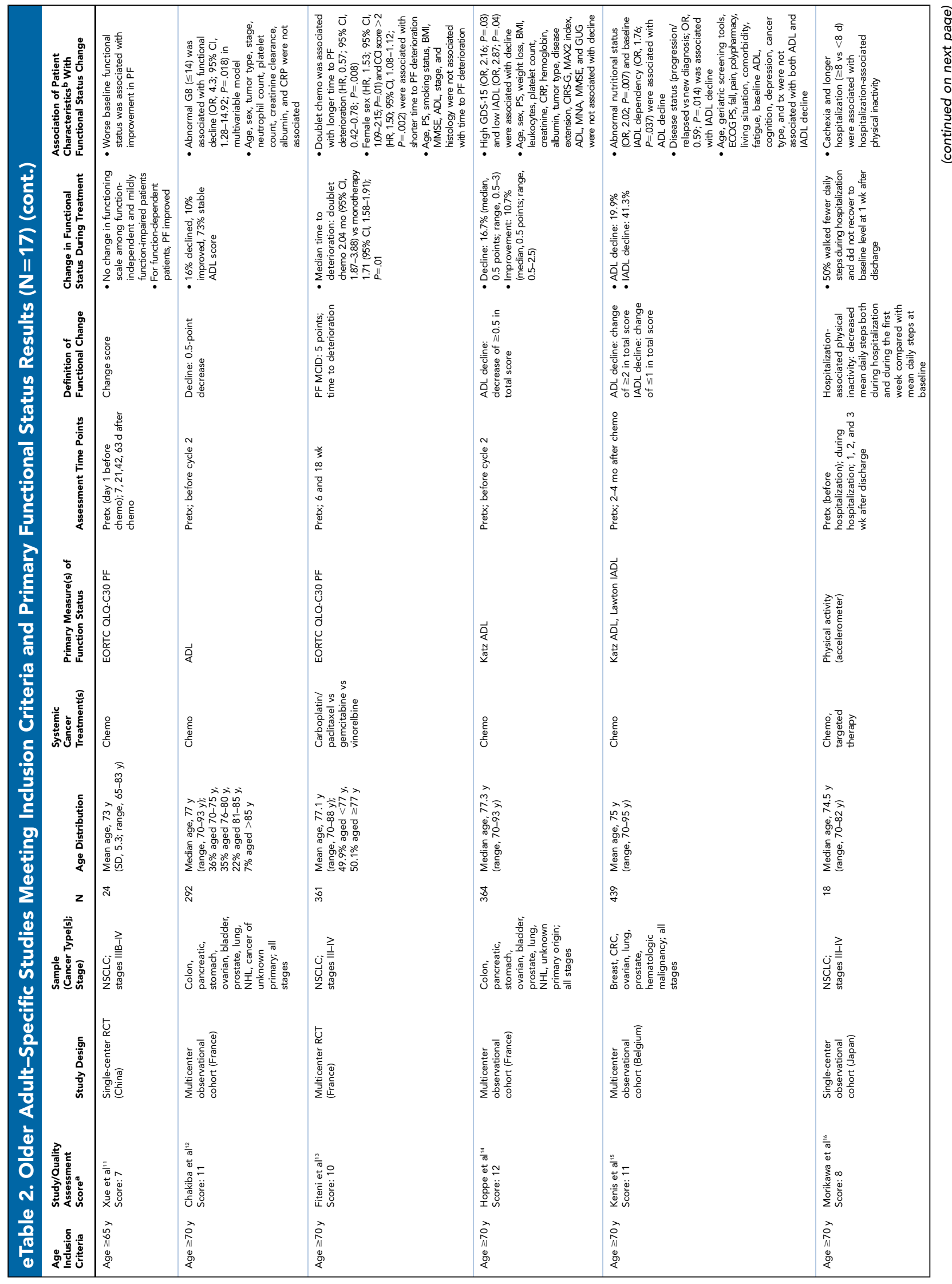




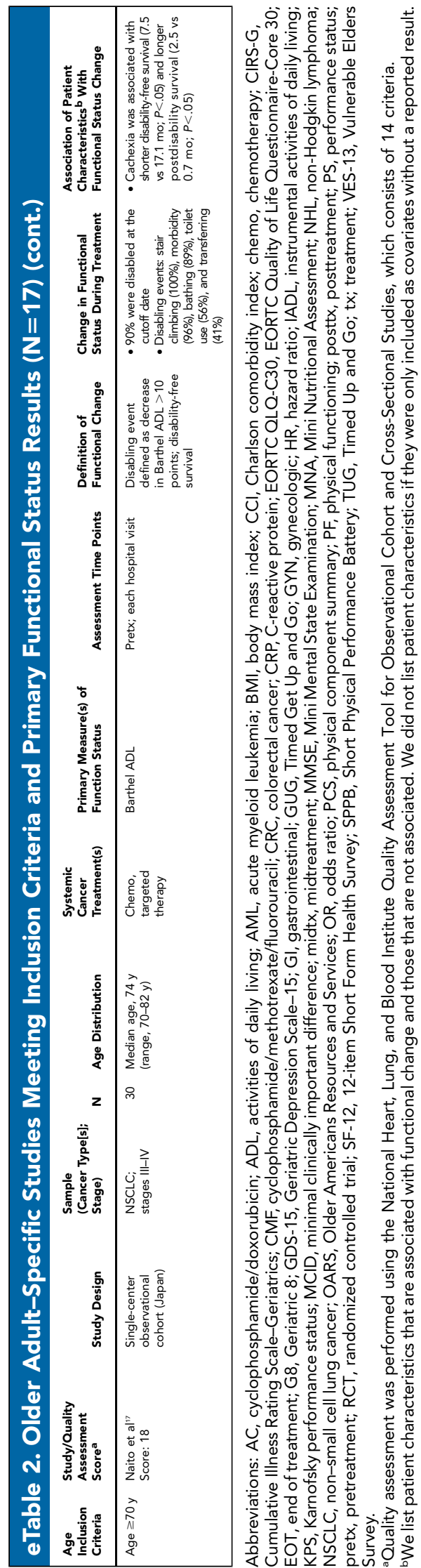




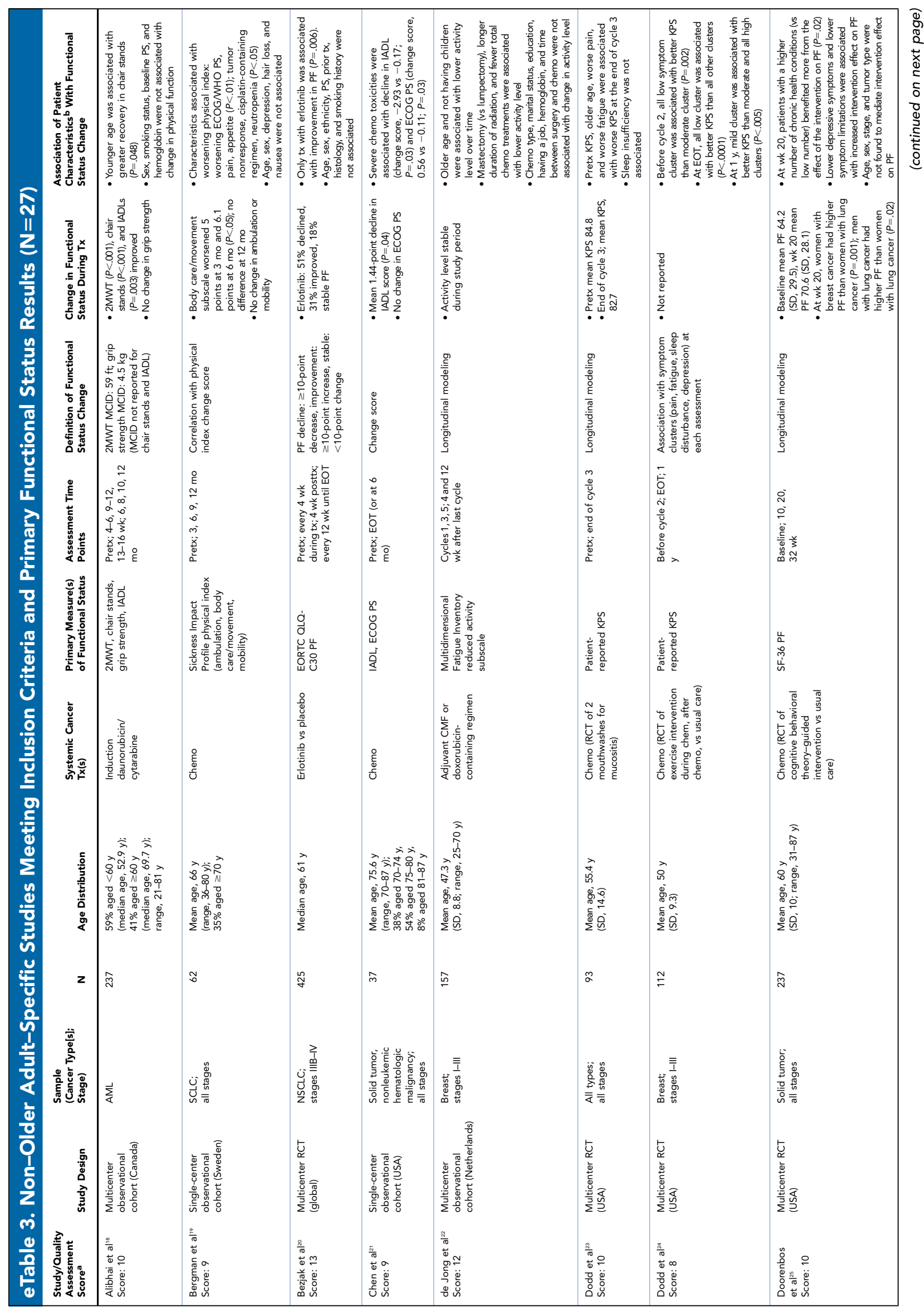




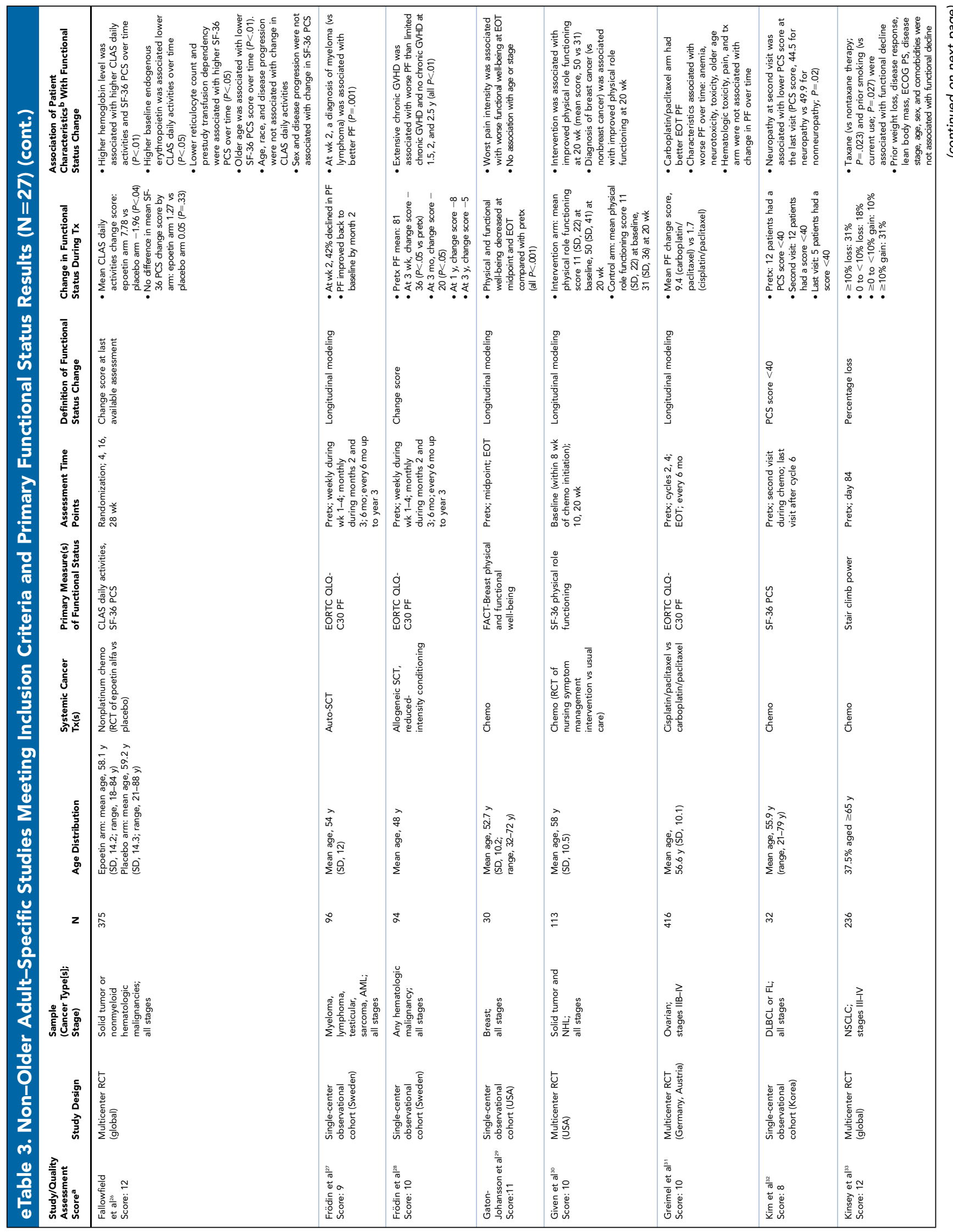




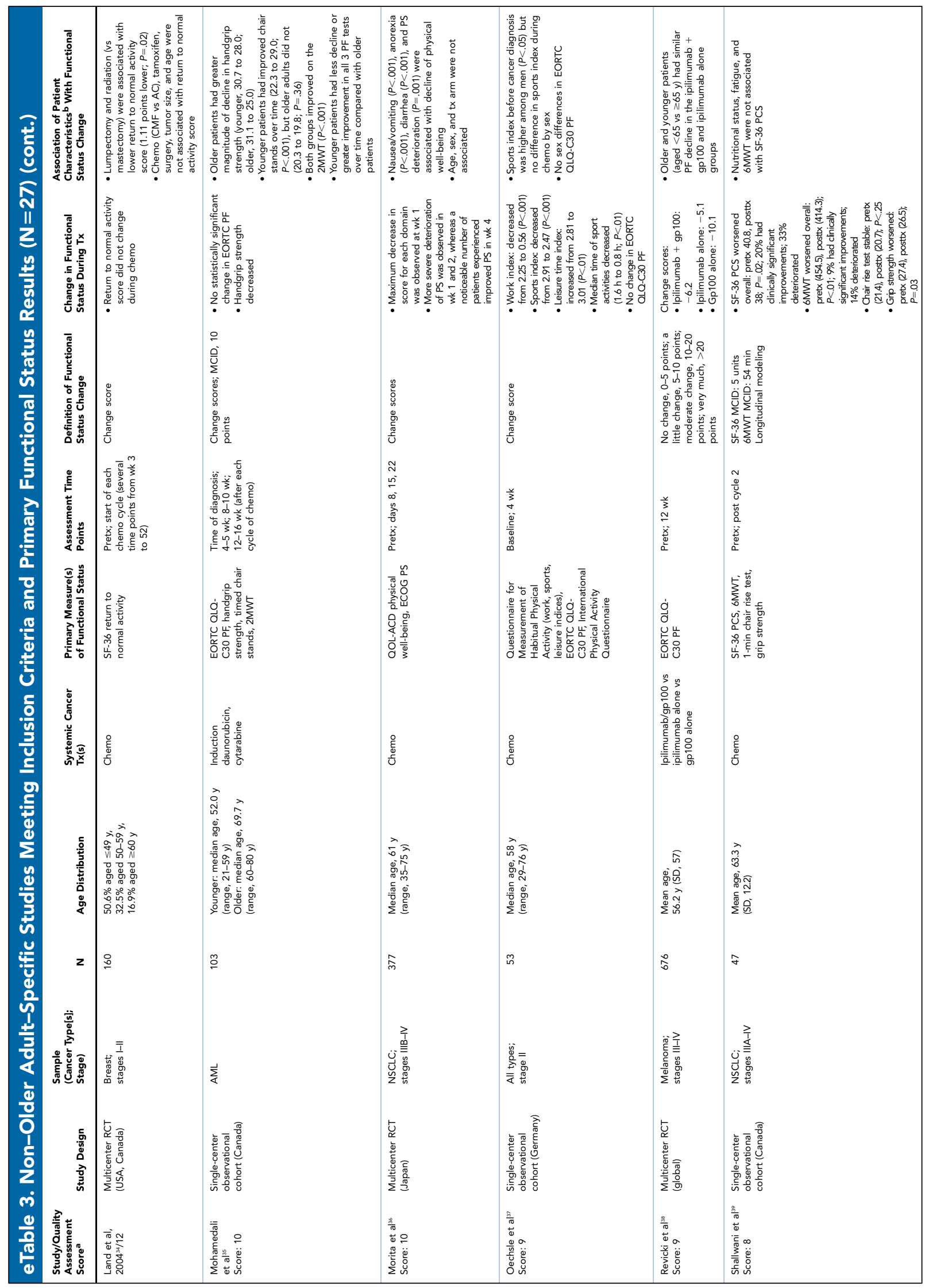




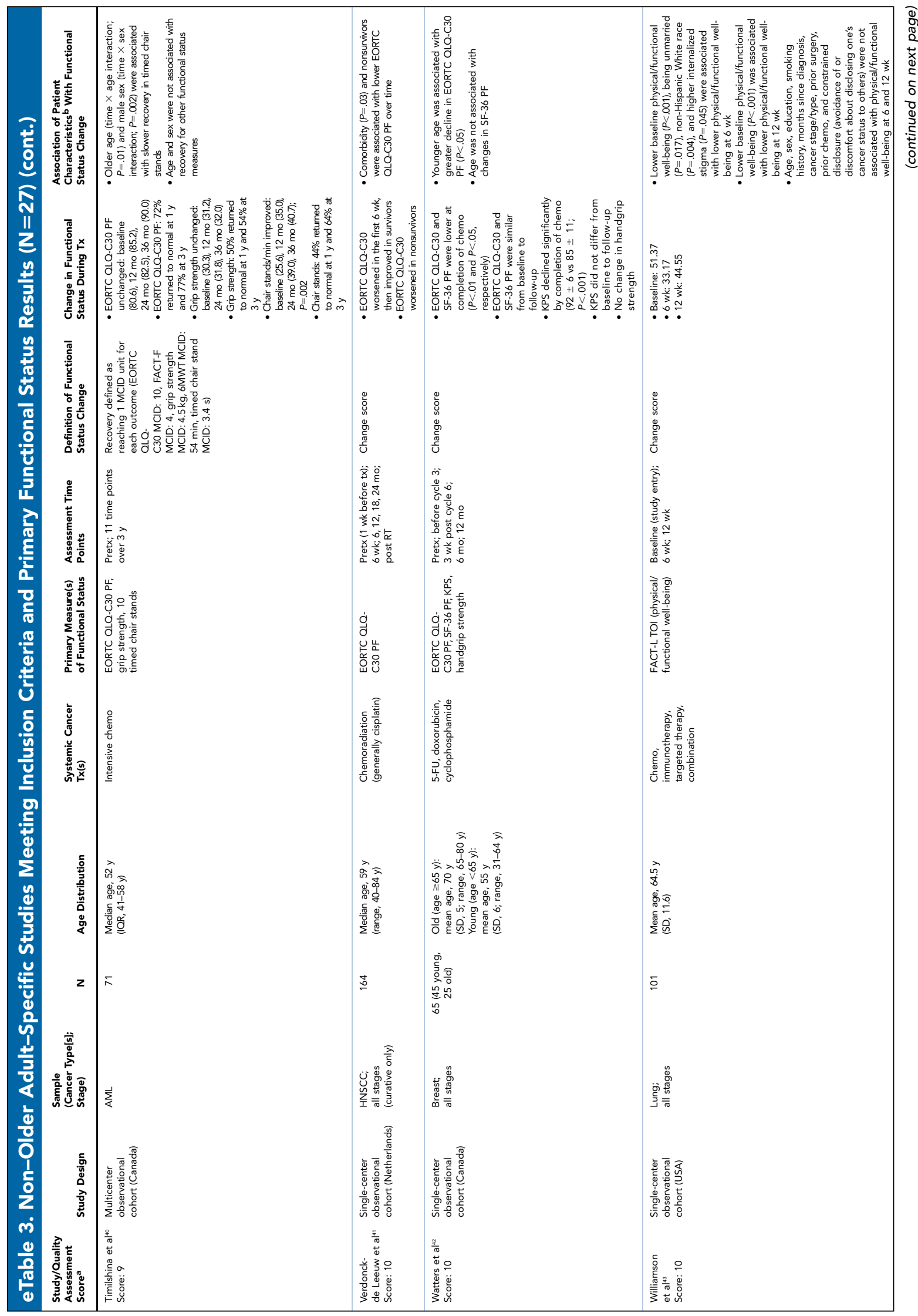




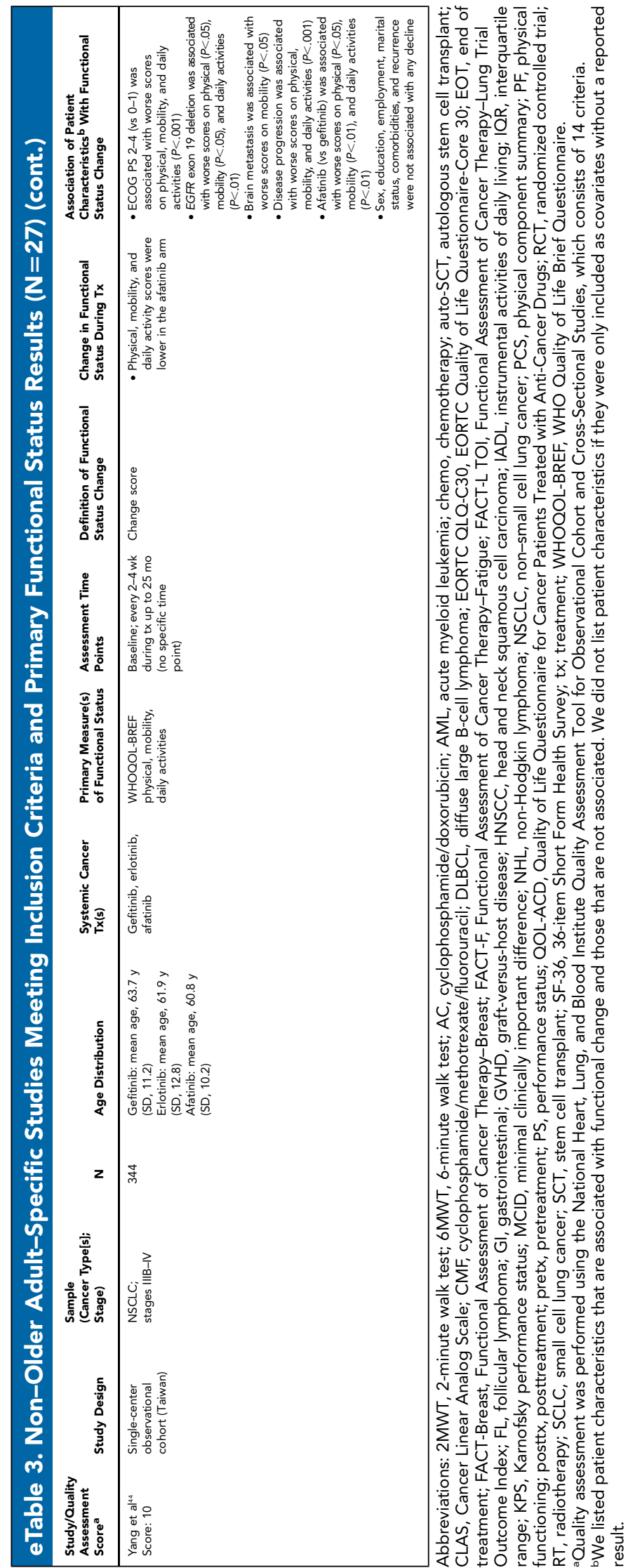




\section{2 - Loh et al}

\section{References}

1. Klepin HD, Tooze JA, Pardee TS, et al. Effect of intensive chemotherapy on physical, cognitive, and emotional health of older adults with acute myeloid leukemia. J Am Geriatr Soc 2016;64:1988-1995.

2. Doni L, Perin A, Manzione L, et al. The impact of anemia on quality of life and hospitalisation in elderly cancer patients undergoing chemotherapy. Crit Rev Oncol Hematol 2011;77:70-77.

3. Gajra A, McCall L, Muss HB, et al. The preference to receive chemotherapy and cancer-related outcomes in older adults with breast cancer CALGB 49907 (Alliance). J Geriatr Oncol 2018;9:221-227.

4. Goodwin JA, Coleman EA, Shaw J. Short Functional Dependence Scale: development and pilot test in older adults with cancer. Cancer Nurs 2006;29:73-81.

5. Hurria A, Soto-Perez-de-Celis E, Allred JB, et al. Functional decline and resilience in older women receiving adjuvant chemotherapy for breast cancer. J Am Geriatr Soc 2019;67:920-927.

6. Manokumar T, Aziz S, Breunis $\mathrm{H}$, et al. A prospective study examining elder-relevant outcomes in older adults with prostate cancer undergoing treatment with chemotherapy or abiraterone. J Geriatr Oncol 2016;7:81-89.

7. Miaskowski C, Wong ML, Cooper BA, et al. Distinct physical function profiles in older adults receiving cancer chemotherapy. J Pain Symptom Manage 2017;54 263-272.

8. Rier HN, Jager A, Meinardi MC, et al. Severe sarcopenia might be associated with a decline of physical independence in older patients undergoing chemotherapeutic treatment. Support Care Cancer 2018;26:1781-1789.

9. Verelst SG, Termorshuizen F, Uyl-de Groot CA, et al. Effect of thalidomide with melphalan and prednisone on health-related quality of life (HRQ $\mathrm{L}$ ) in elderly patients with newly diagnosed multiple myeloma: a prospective analysis in a randomized trial. Ann Hematol 2011;90:1427-1439.

10. Wong ML, Paul SM, Mastick J, et al. Characteristics associated with physical function trajectories in older adults with cancer during chemotherapy. J Pain Symptom Manage 2018;56:678-688.e1.

11. Xue D, Han S, Jiang S, et al. Comprehensive geriatric assessment and traditional Chinese medicine intervention benefit symptom control in elderly patients with advanced non-small cell lung cancer. Med Oncol 2015;32:114.

12. Chakiba C, Bellera C, Etchepare F, et al. The prognostic value of G8 for functional decline. J Geriatr Oncol 2019;10:921-925.

13. Fiteni F, Anota A, Bonnetain F, et al. Health-related quality of life in elderly patients with advanced non-small cell lung cancer comparing carboplatin and weekly paclitaxel doublet chemotherapy with monotherapy. Eur Respir J 2016;48:861-872.

14. Hoppe S, Rainfray M, Fonck M, et al. Functional decline in older patients with cancer receiving first-line chemotherapy. J Clin Oncol 2013;31:3877-3882.

15. Kenis C, Decoster L, Bastin J, et al. Functional decline in older patients with cancer receiving chemotherapy: a multicenter prospective study. J Geriatr Oncol 2017;8: 196-205.

16. Morikawa A, Naito T, Sugiyama M, et al. Impact of cancer cachexia on hospitalization-associated physical inactivity in elderly patients with advanced non-small-cell lung cancer. Asia Pac J Oncol Nurs 2018;5:377-382.

17. Naito T, Okayama T, Aoyama T, et al. Unfavorable impact of cancer cachexia on activity of daily living and need for inpatient care in elderly patients with advanced non-small-cell lung cancer in Japan: a prospective longitudinal observational study. BMC Cancer 2017;17:800

18. Alibhai SM, Breunis $\mathrm{H}$, Timilshina N, et al. Quality of life and physical function in adults treated with intensive chemotherapy for acute myeloid leukemia improve over time independent of age. J Geriatr Oncol 2015;6:262-271.

19. Bergman B, Sullivan M, Sörenson S. Quality of life during chemotherapy for small cell lung cancer. I. An evaluation with generic health measures. Acta Oncol 1991;30: 947-957.

20. Bezjak A, Tu D, Seymour L, et al. Symptom improvement in lung cancer patients treated with erlotinib: quality of life analysis of the National Cancer Institute of Canada Clinical Trials Group Study BR.21. J Clin Oncol 2006;24:3831-3837.

21. Chen H, Cantor A, Meyer J, et al. Can older cancer patients tolerate chemotherapy? A prospective pilot study. Cancer 2003;97:1107-1114.

22. de Jong N, Candel MJ, Schouten HC, et al. Course of the fatigue dimension "activity level" and the interference of fatigue with daily living activities for patients with breast cancer receiving adjuvant chemotherapy. Cancer Nurs 2006;29:E1-13.

23. Dodd MJ, Miaskowski C, Paul SM. Symptom clusters and their effect on the functional status of patients with cancer. Oncol Nurs Forum 2001;28:465-470.

24. Dodd MJ, Cho MH, Cooper BA, et al. The effect of symptom clusters on functional status and quality of life in women with breast cancer. Eur J Oncol Nurs 2010;14: 101-110.

25. Doorenbos A, Given B, Given C, et al. Physical functioning: effect of behavioral intervention for symptoms among individuals with cancer. Nurs Res 2006;55: 161-171.

26. Fallowfield L, Gagnon D, Zagari M, et al. Multivariate regression analyses of data from a randomised, double-blind, placebo-controlled study confirm quality of life benefit of epoetin alfa in patients receiving non-platinum chemotherapy. Br J Cancer 2002;87:1341-1353.

27. Frödin U, Börjeson S, Lyth J, et al. A prospective evaluation of patients' health-related quality of life during auto-SCT: a 3-year follow-up. Bone Marrow Transplant 2011;46:1345-1352.

28. Frödin U, Lotfi K, Fomichov V, et al. Frequent and long-term follow-up of health-related quality of life following allogeneic haematopoietic stem cell transplantation. Eur J Cancer Care (Engl) 2015;24:898-910.

29. Gaton-Johansson F, Watkins CC, Kanu IK, et al. The effects of symptoms on quality of life during chemotherapy in African-American women with breast cancer. J Nat Black Nurses Assoc 2015:26:7-16.

30. Given B, Given CW, McCorkle R, et al. Pain and fatigue management: results of a nursing randomized clinical trial. Oncol Nurs Forum 2002;29:949-956.

31. Greimel ER, Bjelic-Radisic V, Pfisterer J, et al. Randomized study of the Arbeitsgemeinschaft Gynaekologische Onkologie Ovarian Cancer Study Group comparing quality of life in patients with ovarian cancer treated with cisplatin/paclitaxel versus carboplatin/paclitaxel. J Clin Oncol 2006;24:579-586.

32. Kim BJ, Park HR, Roh HJ, et al. Chemotherapy-related polyneuropathy may deteriorate quality of life in patients with B-cell lymphoma. Qual Life Res 2010;19: 1097-1103.

33. Kinsey E, Ajazi E, Wang X, et al. Predictors of physical and functional loss in advanced-stage lung cancer patients receiving platinum chemotherapy. J Thorac Oncol 2018:13:1294-1301.

34. Land SR, Kopec JA, Yothers G, et al. Health-related quality of life in axillary node-negative, estrogen receptor-negative breast cancer patients undergoing AC versus CMF chemotherapy: findings from the National Surgical Adjuvant Breast and Bowel Project B-23. Breast Cancer Res Treat 2004;86:153-164.

35. Mohamedali $\mathrm{H}$, Breunis $\mathrm{H}$, Timilshina $\mathrm{N}$, et al. Older age is associated with similar quality of life and physical function compared to younger age during intensive chemotherapy for acute myeloid leukemia. Leuk Res 2012;36:1241-1248.

36. Morita S, Kobayashi K, Eguchi K, et al. Influence of clinical parameters on quality of life during chemotherapy in patients with advanced non-small cell lung cancer: application of a general linear model. Jpn J Clin Oncol 2003;33:470-476.

37. Oechsle K, Jensen W, Schmidt T, et al. Physical activity, quality of life, and the interest in physical exercise programs in patients undergoing palliative chemotherapy. Support Care Cancer 2011;19:613-619. 
38. Revicki DA, van den Eertwegh AJ, Lorigan $\mathrm{P}$, et al. Health related quality of life outcomes for unresectable stage III or IV melanoma patients receiving ipilimumab treatment. Health Qual Life Outcomes 2012;10:66.

39. Shallwani SM, Simmonds MJ, Kasymjanova G, et al. Quality of life, symptom status and physical performance in patients with advanced non-small cell lung cancer undergoing chemotherapy: an exploratory analysis of secondary data. Lung Cancer 2016;99:69-75.

40. Timilshina N, Breunis $\mathrm{H}$, Tomlinson GA, et al. Long-term recovery of quality of life and physical function over three years in adult survivors of acute myeloid leukemia after intensive chemotherapy. Leukemia 2019;33:15-25.

41. Verdonck-de Leeuw IM, Buffart LM, Heymans MW, et al. The course of health-related quality of life in head and neck cancer patients treated with chemoradiation: a prospective cohort study. Radiother Oncol 2014;110:422-428.

42. Watters JM, Yau JC, O'Rourke K, et al. Functional status is well maintained in older women during adjuvant chemotherapy for breast cancer. Ann Oncol 2003; 14 : 1744-1750.

43. Williamson TJ, Choi AK, Kim JC, et al. A longitudinal investigation of internalized stigma, constrained disclosure, and quality of life across 12 weeks in lung cancer patients on active oncologic treatment. J Thorac Oncol 2018;13:1284-1293.

44. Yang SC, Lin CC, Lai WW, et al. Dynamic changes in quality of life after three first-line therapies for EGFR mutation-positive advanced non-small-cell lung cancer. Ther Adv Med Oncol 2018;10:1758834018755072. 